\title{
ROLE OF BMS IN DES ERA
}

\author{
Guru Chaitanya Kumar C, Phani kotewsar Rao
}

\section{ABSTRACT}

BACKGROUND: DES has gained significant importance in coronary interventions due to its superiority of decrease in target vessel revascularization when compared to BMS. In this DES era, we want to study the role of BMS as it is more economical.

MATERIAL AND METHODS: We have analyzed acute coronary syndrome (ACS) and chronic stable angina patients who underwent BMS implantation between January 2011 to March 2011 under government health scheme of Andhra Pradesh.

RESULTS: We retrospectively analyzed the cardiac events in 4181 BMS implanted patients. 1938 (46.4\%) patients were followed for 365 days. More men than women with 40 to 69 years were there. ST elevation MI was the common presenting symptom in 1902 patients(45.49\% ). 1881 patients (44.98\%) were diabetic. Single vessel disease was more common 2522(60.32\%), Multivessel disease was seen in 210 patients (5.02\%).LAD being the common vessel involved followed by RCA. Primary PCI was done in 320 patients( $7.65 \%)$.

Out of 4181 patients, 9366 lesions were stented with BMS, stainless steel BMS was used in 4988(53.26\%) and cobalt chromium BMS was used in 4378 (46.74\%) patients.

Out of 4181 patients, 1938 patients (46.4\%) were followed up of 1yr, post PCI 686 (35.4\%) patients had worsening angina, 226(11.66\%) patients had worsening heart failure, 17 $(0.88 \%)$ patients had repeat STEMI, 11(0.56\%)patients had repeat NSTEMI, $16(0.82 \%)$ patients had subacute stent thrombosis, $27(1.39 \%)$ patients developed late stent thrombosis, 51 patients $(2.63 \%)$ underwent repeat target vessel revascularization(TVR). $52(2.68 \%)$ patients died due to cardiac cause with in one year of follow up .

CONCLUSIONS: Our study show that even in present era of DES , BMS implantation is effective and associated with less mortality and less stent thrombosis and less chances of target vessel revascularization with the limitations (as it was telephonic follow up).

KEY WORDS: Drug Eluting Stents, Bare Metal Stents, Major cardiac events - MACE

Article received on 5 Jan 2016, published on 25 JAN 2016.

Guru Chaitanya Kumar $C^{1}$, Phani kotewsar Rao ${ }^{2}$,

${ }^{1}$ Senior resident, Departments of Cardiology, NIMS, India

${ }^{2}$ Excutive officer, Planning \& coordination wing, Aarogyasri Trust

Corresponding author: Guru Chaitanya Kumar C

Email: chaitu2041985@gmail.com

\section{INTRODUCTION}

Percutaneous coronary intervention (PCI) with stent implantation has replaced balloon angioplasty, due to a reduction in the incidence of restenosis. However, an instent restenosis rate of $10-40 \%$ has been a significant problem in bare-metal stent (BMS) implantation . Recently developed drug-eluting stents (DESs) have reduced the rate of restenosis. However, the higher cost of DESs and the risk of stent thrombosis are major limiting factors. The health policy of Andhra Pradesh State in India is to provide minimum treatment facility for below poverty line coronary artery disease patients requiring $\mathrm{PCI}$, so it is funding for low cost BMS implantation during PCI. We retrospectively studied the cardiac events in BMS implanted patients.

\section{METHODS:}

STUDY DESIGN: We utilized a retrospective crosssectional analysis of prospective data from the government health scheme, which includes follow-up data on death, MI, hospitalizations, cardiac events, and medication usage (MACE).

PATIENT POPULATION: During 2011, 13897 patients have undergone PCI under government health scheme in various geographically diverse centers across the Andhra Pradesh. We have analyzed 4181 patients who underwent BMS implantation between January 2011 to March 2011 . All patients presenting with acute coronary syndrome (ACS) and chronic stable angina were included in the study.

We included all patients who underwent PCI under government health scheme during their index hospitalization and who received only BMS and patients who received both BMS and DES or no stent were excluded . End points were mortality, morbidity, target vessel $\mathrm{PCI}$,stent thrombosis and subsequent CABG surgery.

\section{RESULTS:}


We retrospectively analyzed the cardiac events in 4181 BMS implanted patients. 1938 (46.4\%) patients were followed for 365 days. Demographic characteristics were mentioned in the Table $1 \& 2$.

Table 1: Patients characteristics.

\begin{tabular}{|c|c|}
\hline Variables & Number (percentage) \\
\hline $\begin{array}{c}\text { Age (yrs) } \\
<40 \\
40-49 \\
50-59 \\
60-69 \\
70-79 \\
>80 y r s \\
\text { Interquartile range }\end{array}$ & $\begin{array}{l}525(12.6 \%) \\
1123(26.9 \%) \\
1173(28.1 \%) \\
1041(24.9 \%) \\
297(7.1 \%) \\
22(0.5 \%) \\
56.2+10.7\end{array}$ \\
\hline $\begin{array}{l}\text { Gender } \\
\text { Male } \\
\text { Female } \\
\text { M:F }\end{array}$ & $\begin{array}{l}2739(65.5 \%) \\
1442(34.5 \%) \\
1.9: 1\end{array}$ \\
\hline Hypertension & $1697(40.58 \%)$ \\
\hline Diabetes mellitus & $1881(44.98 \%)$ \\
\hline Smoking & $1441(34.46 \%)$ \\
\hline $\begin{array}{l}\text { Ejection fraction(\%) } \\
<35 \\
35-44 \\
45-54 \\
>55 \\
\text { Interquartile range }\end{array}$ & $\begin{array}{l}310(7.4 \%) \\
522(12.5 \%) \\
1583(37.9 \%) \\
1766(42.2 \%) \\
48+17\end{array}$ \\
\hline $\begin{array}{l}\text { Mode of presentation } \\
\text { STEMI } \\
\text { NSTEMI } \\
\text { UNSTABLE } \\
\text { ANGINA } \\
\text { CSA }\end{array}$ & $\begin{array}{l}1902(45.49 \%) \\
889(21.26 \%) \\
913(21.84 \%) \\
477(11.4 \%)\end{array}$ \\
\hline
\end{tabular}

Table 2 : Patient characteristics

\begin{tabular}{|l|l|}
\hline Variables & Number (percentage) \\
\hline CCF & $268(6.4 \%)$ \\
\hline Cardiogenic shock & $144(1.04 \%)$ \\
\hline Prior MI & $342(8.18 \%)$ \\
\hline Prior PCI & $226(5.4 \%)$ \\
\hline Prior CABG & $32(0.76 \%)$ \\
\hline Renal failure & $297(7.1 \%)$ \\
\hline
\end{tabular}

In 4181 patients, 9366 lesions were stented. Procedure data and medications used were mentioned in the following Table $2 \& 3$.
Table 3: Medications used during discharge and follow up

\begin{tabular}{|l|l|}
\hline Drug Name & Number \\
\hline Aspirin & $4100(98.06 \%)$ \\
Thienopyridine & $3980(95.19 \%)$ \\
Statins & $3978(95.14 \%)$ \\
ACEI/ARBS & $2998(71.70 \%)$ \\
Beta blockers & $2784(66.58 \%)$ \\
\hline
\end{tabular}

One year follow up was done in 1938 (46.4\%) patients through standardized telephone interviews. MACE occurred in $1109(57.2 \%)$ patients. After BMS implantation 686 (35.4\%) patients had worsening angina, $226(11.66 \%)$ patients had worsening heart failure, 17 $(0.88 \%)$ patients had repeat STEMI, $11(0.56 \%)$ patients had repeat NSTEMI, 51 (2.63\%) patients had repeat $\mathrm{PCI} / \mathrm{CABG}, 75$ (3.87\%) patients died with in one year, 52 $(2.68 \%)$ patients died due to cardiac cause, $16(0.82 \%$ )patients developed subacute stent thrombosis, 27 $(1.39 \%)$ patients developed late stent thrombosis (Table 4).

Table 4 : Post PCI procedure follow up telephonically at one year

\begin{tabular}{|l|l|}
\hline Variables & Number (percentage) \\
\hline Worsening angina & $686(35.4 \%)$ \\
\hline Worsening heart failure & $226(11.66 \%)$ \\
\hline Repeat STEMI & $17(0.88 \%)$ \\
\hline Repeat NSTEMI & $11(0.56 \%)$ \\
\hline $\begin{array}{l}\text { Stent thrombosis } \\
\text { Subacute } \\
\text { Late }\end{array}$ & $16(0.82 \%)$ \\
\hline $\begin{array}{l}\text { Target vessel } \\
\text { revascularization }\end{array}$ & $51(1.39 \%)$ \\
\hline Cardiac death & $52(2.68 \%)$ \\
\hline
\end{tabular}

\section{DISCUSSION:}

The development of bare metal stents (BMS) was a major advance over balloon angioplasty in the management of symptomatic coronary artery disease. BMS prevented restenosis by attenuating early arterial recoil and contraction. However, the rate of clinically-indicated target lesion repeat revascularization due to restenosis at one year remains relatively high at 10 to 20 percent of patients and is often due to excessive growth of 
neointima [1-3] Drug-eluting stents (DES) were developed to reduce the relatively high rate of restenosis and subsequent repeat revascularization with BMS. DES consists of a metallic stent backbone, an antiproliferative drug, and a polymer that serves as the vehicle for the drug and also controls the drug release rate. The drug inhibits excessive growth of neointima, a major cause of restenosis. Since each DES is unique, differences may be observed with respect to deliverability (ease of placement), efficacy (prevention of restenosis), and safety (rates of stent thrombosis)[4-9].

Clinical trials have confirmed a reduction of as much as 50 to 70 percent in target lesion revascularization by DES compared to BMS. These findings have led to the preferential use of DES in the majority of percutaneous coronary intervention. Risk of stent thrombosis are major limiting factors with use of DES, hence require longer period of dual antiplatelet therapy to prevent stent thrombosis. So DES are not appropriate for all patients. Higher cost of DESs in comparison with BMS is another major limiting factor. Though several studies have shown DES to be superior to BMS in terms of restenosis rates and target vessel revascularization $[10,11]$.This study has analyzed the major cardiac events in patient with coronary artery disease implanted with BMS during follow up of 1yrs post BMS implantation and to assess the role of BMS in the present era of DES. In the present study coronary artery disease was more common in men than women, ST elevation MI was the common presenting symptom in 1902patients $(45.49 \%$ ),1881 patients(44.98\%) were diabetic. In sub analysis of PRODIGY trial [12], $72 \%$ of patients with CAD were men, $34 \%$ of patients presented with STEMI, $24 \%$ of patients were diabetic. In Puymirat et al [13] study 69\% of patients with coronary artery disease were men, stable angina was the common presenting symptom $62 \%$,STEMI was present in $28 \%$.

In the present study single vessel disease was more common 2522(60.32\%) ,Multivessel disease was seen in 210 patients $(5.02 \%)$.LAD being the common vessel involved followed by RCA. primary PCI was done in 320 patients(7.65\%).In PRODIGY trial[12] multivessel disease was more common and LAD being the most common vessel involved. In Puymirat et al[13] LCX and $\mathrm{LAD}$ are the most common vessels involved. In the present study out of 4181 patients, 9366 lesions were stented with BMS, stainless steel BMS was used in
$4988(53.26 \%)$ and cobalt chromium BMS was used in 4378 (46.74\%) patients.

Out of 4181 patients, 1938 patients (46.4\%) were followed up of $1 \mathrm{yr}$, post PCI $686(35.4 \%)$ patients had worsening angina, 226(11.66\%) patients had worsening heart failure. In Doyle et al [14] study, clinical restenosis was found in $18.1 \%$ patients. The higher rates of worsening angina(35.4\%) in the present study may be due to restenosis, stent thrombosis, coronary spasm, incomplete revascularization, micro vascular dysfunction[15,16]

In the present study $17(0.88 \%)$ patients had repeat STEMI,11(0.56\%) patients had repeat NSTEMI. In Puymirat et al [13] study, $8 \%$ patients had non-fatal MI after coronary revascularization. In Kurz et al [17] study ,5.5\% had non-fatal MI after PCI. Metanalysis of EXAMINATION and COMFORTABLE-AMI trials by Sabate et al [18] repeat MI rates were $3.8 \%$ \& $2 \%$ and Target vessel reinfarction rates were $1.1 \%$ \& $2 \%$. In the present study $16(0.82 \%)$ patients had sub-acute stent thrombosis,27(1.39\%)patients developed late stent thrombosis. In Doyle, et al [14] study, incidence of stent thrombosis was $0.5 \%$ at 30 days, $0.8 \%$ at 1 year. In Tada et al. [19] study, stent thrombosis occurred in $0.7 \%$ patients at 30 days, $1.5 \%$ in 3 years of follow up.

In the present study 51 patients (2.63\%) underwent repeat target vessel revascularization (TVR). In Puymirat et al [13]study, $17 \%$ of patients underwent TVR .In Kurz et al [17] study $6.2 \%$ patients underwent TVR .Metanalysis by Sabate et al [18] , 8.8\% \& $10.6 \%$ patients underwent TVR but only $5.8 \%$ \& $4.8 \%$ patients underwent target lesion revascularization.

In the present study,52 (2.68\%)patients died due to cardiac cause with in one year of follow up. In Puymirat et al [13]study $10 \%$ patients died during follow up of 3 yrs. In Kurz et al [17] study cardiac death was seen in $7.5 \%$ patients .The low death rate in the present study may be due to better drug compliance, low incidence of stent thrombosis and low rates of repeat MI.

Limitations of the study

The follow up of the patients was telephonically. So, the heart failure may over diagnosed as clinical examination was not done and patients who had worsening of dyspnea were labeled as HF patients. Even in symptomatic patients, follow up angiograms were not at one year to know the cause of symptom, by that restenosis may be under estimated and HF may be over diagnosed. 


\section{CONCLUSIONS}

Our study show that even in present era of DES, BMS implantation is effective and associated with less mortality and less stent thrombosis and less chances of target vessel revascularization with the limitations mentioned above.

\section{REFERENCES:}

1. Fischman DL, Leon MB, Baim DS, et al. A randomized comparison of coronary-stent placement and balloon angioplasty in the treatment of coronary artery disease. Stent Restenosis Study Investigators. N Engl J Med 1994; 331:496.

2. Serruys PW, de Jaegere P, Kiemeneij F, et al. A comparison of balloon-expandable-stent implantation with balloon angioplasty in patients with coronary artery disease. Benestent Study Group. N Engl J Med 1994; 331:489.

3. Cutlip DE, Chauhan MS, Baim DS, et al. Clinical restenosis after coronary stenting: perspectives from multicenter clinical trials. J Am Coll Cardiol 2002; 40:2082.

4. Babapulle MN, Joseph L, Bélisle P, et al. A hierarchical Bayesian meta-analysis of randomised clinical trials of drug-eluting stents.Lancet 2004;364:583-91.

5. Spaulding C, Daemen J, Boersma E, et al. A pooled analysis of data comparing sirolimuseluting stents with bare-metal stents. N Engl J Med 2007;356: 989-97.

6. Stone GW, Moses JW, Ellis SG, et al. Safety and efficacy of sirolimusand paclitaxel- eluting coronary stents. N Engl J Med 2007;356:998-1008.

7. Kastrati A, Mehilli J, Pache J, et al. Analysis of 14 trials comparing sirolimus eluting stents with bare-metal stents. N Engl J Med 2007;356:1030-9.
8. Spaulding C, Henry P, Teiger E, et al. Sirolimuseluting versus uncoated stents in acute myocardial infarction. $\mathrm{N}$ Engl J Med 2006;355:1093-104.

9. Laarman GJ, Suttorp MJ, Dirksen MT, et al. Paclitaxel-eluting versus uncoated stents in primary percutaneous coronary intervention. $\mathrm{N}$ Engl J Med 2006;355:1105-13.

10. Yeh RW, Normand SL, Wolf RE, et al. Predicting the restenosis benefit of drug-eluting versus bare metal stents in percutaneous coronary intervention. Circulation 2011;124(14):1557-64.

11. Stone GW, Lansky AJ, Pocock SJ, et al. Paclitaxel-eluting stents versus bare-metal stents in acute myocardial infarction. N Engl J Med 2009;360(19):1946-59.

12. valgimigli et al. two-year outcomes after first- or second-generation drug-eluting or bare-metal stent implantation in all-comer patients undergoing percutaneous coronary intervention. jacc :cardiovascular interventions, vol.7,no.1 ,2014:20-8

13. Etienne Puymirat, MD, Fabio Mangiacapra et al. Long-term clinical outcome in patients with small vessel disease treated with drug-eluting versus bare-metal stenting. American Heart Journal 2011, Nov;162(5):907-13.

14. Brendan Doyle Outcomes of Stent Thrombosis and Restenosis During Extended Follow-Up of Patients Treated With Bare-Metal Coronary Stents.Circulation. 2007;116:2391-2398.)

15. Antonio Abbate et al. Recurrent angina after coronary revascularization: a clinical challengeEuropean Heart Journal (2007) 28, 1057-1065

16. Paolo Izzo et al Recurrent angina after coronary angioplasty: mechanisms, diagnostic and therapeutic options. Eur Heart J Acute Cardiovasc Care. 2012 Jun; 1(2): 158-169. 
17. Kurz et al. Improved outcomes of elderly patients treatedwith drug-eluting versus bare metal stents in large coronary arteries: Results from the BAsel Stent Kosten-Effektivitäts Trial PROspective Validation Examination randomized trial. Am Heart J 2015;170:787795.e1

18. Sabaté et al. Comparison of Newer-Generation Drug-Eluting With Bare-Metal Stents in Patients With Acute ST-Segment Elevation Myocardial Infarction J Am Coll Cardiol Intv 2014;7:55-63

19. Tada et al .,Risk of Stent Thrombosis Among Bare-Metal Stents,First-Generation Drug-Eluting Stents, and Second-Generation Drug-Eluting Stent. (J Am Coll Cardiol Intv 2013;6:1267-74) 